\title{
O ENSINO DA GEOMORFOLOGIA COM A PRODUÇÃO DE MATERIAIS DIDÁTICOS
}

\author{
Thais dos Anjos Soares ${ }^{(a)}$, Simone Cardoso Ribeiro ${ }^{(b)}$ \\ (a) Estudante de Licenciatura em Geografia, Estagiária no Laboratório de Geomorfologia e Pedologia - \\ GEOPED/URCA, thaisdosanjos05@gmail.com \\ (b) Orientadora - Professora Associada - DEGEO/URCA, simone.ribeiro@urca.br
}

\section{EIXO: GEOGRAFIA FÍSICA - CURRÍCULO, FORMAÇÃO E PRÁTICAS DE ENSINO}

\begin{abstract}
Resumo
O ensino da dinâmica geomorfológica é essencial para que o aluno compreenda de forma estimulante a lógica das mudanças da superfície do planeta e suas influências no seu dia a dia. O objetivo deste trabalho é produzir junto com a turma do $7^{\circ}$ ano da Escola de Ensino Infantil e Fundamental Maria Pedrina em Juazeiro do Norte - CE, um material didático, para facilitar o aprendizado de Geomorfologia no qual eles tenham noção básica das modificações pelas quais passam as formas de relevo. Na construção deste trabalho foi feito um levantamento bibliográfico temático, após o qual se aplicou um questionário para a turma; na $3^{\mathrm{a}}$ fase, fez-se uma abordagem didática sobre o conteúdo relevo e suas formas para depois focar-se na produção do material. Identificou-se com os dados coletados no questionário que os alunos não tinham um bom conhecimento sobre o assunto antes de abordar o conteúdo.
\end{abstract}

Palavras chave: Dinâmica geomorfológica, Formas de relevo, Didática.

\section{Introdução}

Na dinâmica físico-ambiental do espaço, a chamada área física da geografia, podemos citar entre muitas, uma importante ciência, a geomorfologia, que é a responsável por estudar as diversas formas de relevo da Terra. Uma disciplina que nos faz compreender várias mudanças do meio ambiental em que vivemos e que também está ligada ao meio social, devendo assim, ter seu conteúdo mais discutido no ensino básico. Como explica Batista e Sousa (2012, p.18):

O ensino de geomorfologia deveria ser mais valorizado, uma vez que o estudo ambiental e a compreensão do meio onde se vive se dá sobre o relevo. É o relevo quem determina a infraestrutura das cidades, das rodovias, ferrovias, o uso e ocupação das terras, os processos erosivos, entre outros fatores fundamentais para a vida humana. É claro que outros fatores físicos atuam, mas o relevo é sempre uma peça fundamental na análise da paisagem.

$\mathrm{Na}$ disciplina de geografia escolar, a geomorfologia é indispensável para o crescimento do aluno desde o nível fundamental, para que este possa conhecer as paisagens, e aprender a importância do relevo na organização espacial humana. Assim, o ensino da geomorfologia poderia ser mais apreciado, pois possibilita o crescimento do aluno no conhecimento das paisagens que o cercam. De acordo com esse pensamento, para facilitar o aprendizado no âmbito escolar, aulas produtivas e dinâmicas, são as melhores opções para os educadores explorarem esta temática em suas aulas. Como indica Falconi (2004, p.6):

Para isso os professores devem criar situações de aprendizagem que estimulem a observação, a descrição, a experimentação, a representação, a comparação e a construção de explicações, analogia e síntese dessas relações, além de investigar conhecimentos 


\section{OS DESAFIOS DA GEOGRAFIA FÍSICA NA FRONTEIRA DO CONHECIMENTO \\ Instituto de Geociências - Unicamp \\ Campinas - SP \\ 28 de Junho à 02 de Julho de 2017}

adquiridos pelos alunos no núcleo familiar ou por outros meios de comunicação, a fim

de criar situações mais significativas.

Com este método, estimularia o aluno ao raciocínio, à observação, à caracterização e outros meios que relacionariam com as paisagens, formando alunos críticos. E para facilitar este ensinamento, o professor precisa exercer uma linguagem de fácil entendimento, pois a linguagem científica, os alunos podem não compreender e não considerar. Assim como Falconi (2004, p.9) mais uma vez afirma: "Contudo, $o$ professor deve ter o cuidado de não tratar os conteúdos de forma muito específica. Seu papel é criar situações na qual os alunos desenvolvam um conhecimento crítico acerca do mundo, sem pretender tornálos geógrafos."

As estratégias de ensino são o modo de organizar o saber didático, apresentando diversas técnicas e recursos que possibilitem o alcance dos objetivos propostos para a atividade (FREITAS, 2009). Aulas dinâmicas mantém a atenção dos alunos, e existem diversas formas de propor isso. Com a utilização e produção de materiais didáticos, estimula-se o aluno a aprender de verdade, como por exemplo, o livro escolar, cartilhas, maquetes e outras produções envolvendo conhecimento, pois os materiais didáticos devem educar garantindo o crescimento do educando. Entretanto, essa estimulação deve se integrar entre o professor e o aluno, como argumenta Silva e Giordani (2009, p.2):

A interação entre o profissional da educação e seu aluno precisa ser levada em consideração, contudo, esta deve ser prevista para que porte o desenvolvimento contemporâneo de ambos. E, isso pode ser mediado pela construção de aprendizagem que junto à materiais consolida e transforma as pessoas com o conhecimento propiciado, dando à ele sentido e prazer ao ser realizado.

O objetivo deste trabalho é produzir junto com uma turma do $7^{\circ}$ ano do Ensino Básico, materiais didáticos que facilitem seu aprendizado de geomorfologia, possibilitando a compreensão sobre as formas de relevo, representando assim, a realidade dessas formas através deste material, que no caso, na maquete.

\section{Metodologia}

O projeto foi aplicado na Escola de Ensino Infantil e Fundamental Maria Pedrina, localizada na zona rural de Juazeiro do Norte -CE, na turma do $7^{\circ}$ ano, com alunos entre 11 à 18 anos de idade. Para a preparação do vigente estudo, foi feito um levantamento bibliográfico para conhecer como alguns pesquisadores tratam o ensino da geomorfologia nas escolas e seus métodos com materiais didáticos auxiliares que propõem uma aula dinâmica para seus alunos baseados no conteúdo visto em sala de aula. Dentre esse levantamento, foi importante conhecer trabalhos de diferentes autores sobre a utilização/produção de materiais didáticos como uma forma diferente de ensinar a geomorfologia.

Primeiramente foi aplicado um pequeno questionário contendo 06 questões, duas questões para coletar dados pessoais e as outras quatro como um diagnóstico a ser avaliado o conhecimento prévio sobre o relevo, e para saber também se nas suas aulas de geografia houve dinamicidade na aprendizagem. Logo em seguida, foi explanado o conteúdo sobre o "relevo e suas formas" com a utilização de slide, para abordar conceitos necessários, e imagens. Após finalizar as explanações, foram feitas perguntas simples dirigidas ao conteúdo visto, apresentando também, imagens de maquetes prontas retirados através de um blog da professora Simone Nalin, representando diferentes formas de relevo (depressão, planície, serras, etc.) nas quais deveriam se basear para criar representações tridimensionais - de planalto, planície, depressão e montanhas, trabalhados com materiais escolares comuns: cola branca, jornais, tintas na cor verde, vermelho e azul e a cor marrom feita (verde+vermelho), pincéis e também água para utilizar na moldagem do relevo com o jornal e cola. A turma foi dividida em dois grupos, onde ambos apresentaram suas maquetes. 


\section{OS DESAFIOS DA GEOGRAFIA FÍSICA NA FRONTEIRA DO CONHECIMENTO \\ Instituto de Geociências - Unicamp \\ Campinas - SP \\ 28 de Junho à 02 de Julho de 2017}

\section{Resultados e Discussões}

Analisando o conhecimento prévio dos alunos de acordo com suas respostas no questionário, foi possível identificar que, com relação ao conteúdo sobre relevo, eles não tiveram um bom aproveitamento e aprofundamento durante suas aulas de geografia até agora, e também nunca presenciaram e/ou participaram de uma aula dinâmica. Desta maneira, pode-se afirmar que as respostas foram incompletas, não consideráveis exatamente erradas.

Na primeira questão, logo antes de se iniciar perguntas sobre relevo, buscava saber primeiramente sobre "O que é a geografia para você?", muitos responderam ser o "estudo sobre o relevo" ou "algo geográfico". Com relação à estas respostas, nota-se que eles ainda não têm noção sobre o que seja esta disciplina e o que estuda, para antes saber sobre o que é o relevo. Na próxima questão, chave para o estudo, perguntou-se "O que é o relevo?", muitos responderam ser "um espaço geográfico", o que não foi considerável, pois espaço geográfico não é conceito para relevo. Na seguinte questão, "No decorrer de suas aulas de geografia, você conseguiu aprender o conteúdo repassado sobre o relevo? Os professores da sua série atual e das séries anteriores fizeram dinâmicas para a fixação do conteúdo?" na primeira pergunta, foi obtido respostas do tipo "não me lembro", e na segunda pergunta, todos responderam nunca ter tido uma aula dinâmica, sem ao menos saber o que era. Sobre a "Importância de estudar o relevo", as respostas foram: "É que a gente aprende mais", "aprender sobre o mundo", "para estudar o espaço" "sei lá", essas foram as principais respostas dos alunos, sobre a importância de estudar o relevo.

Com base nos resultados do diagnóstico, pode-se afirmar que, os alunos não possuem conhecimento sobre relevo e também nunca tiveram aulas dinâmicas na disciplina de Geografia, o que dificulta muito o seu aprendizado e compreensão da realidade e conhecimento do mundo em que vivemos.

No início da abordagem do conteúdo, mais uma vez foi feita a seguinte pergunta “O que é o relevo?", mas dessa vez, oral. Entre essa e outras perguntas, foram feitas, como "O que é o relevo e o solo?" as respostas não foram satisfatórias. Durante a aula, conceitos, exemplos e imagens foram repassadas e todos atenciosos compreendiam depois de saber sobre o que seria o relevo e suas formas. Ao final, novamente as perguntas para eles, todos conseguiam responder com mais facilidade e corretamente. As imagens de maquetes trabalhadas pela professora Simone Lanin (2012) retiradas de seu blog- Geografia da professora Simone, foram expostas para eles se basearem e produzirem maquetes com as formas de relevo, que ficaram a livre escolha de qual tipo iriam reproduzir tridimensionalmente em grande escala. Um grupo utilizou as quatro formas de relevo (planalto, planície, depressão e montanhas) incluindo rios e vegetação (figura 1), enquanto o outro grupo produziu também quatro formas (planalto, planície, montanhas e vulcão) incluindo também rios e vegetação (figura 2) .

Após a produção das maquetes, cada grupo apresentou seus trabalhos, identificando cada espaço criado e quais formas de relevo utilizaram. Por fim, o conteúdo foi compreendido e bem representado nas maquetes, demonstrando a facilitação de aprendizado da geomorfologia, resultande da dinâmica, da arte, do raciocínio, do conhecimento e da realidade representada através de materiais pedagógicos. 

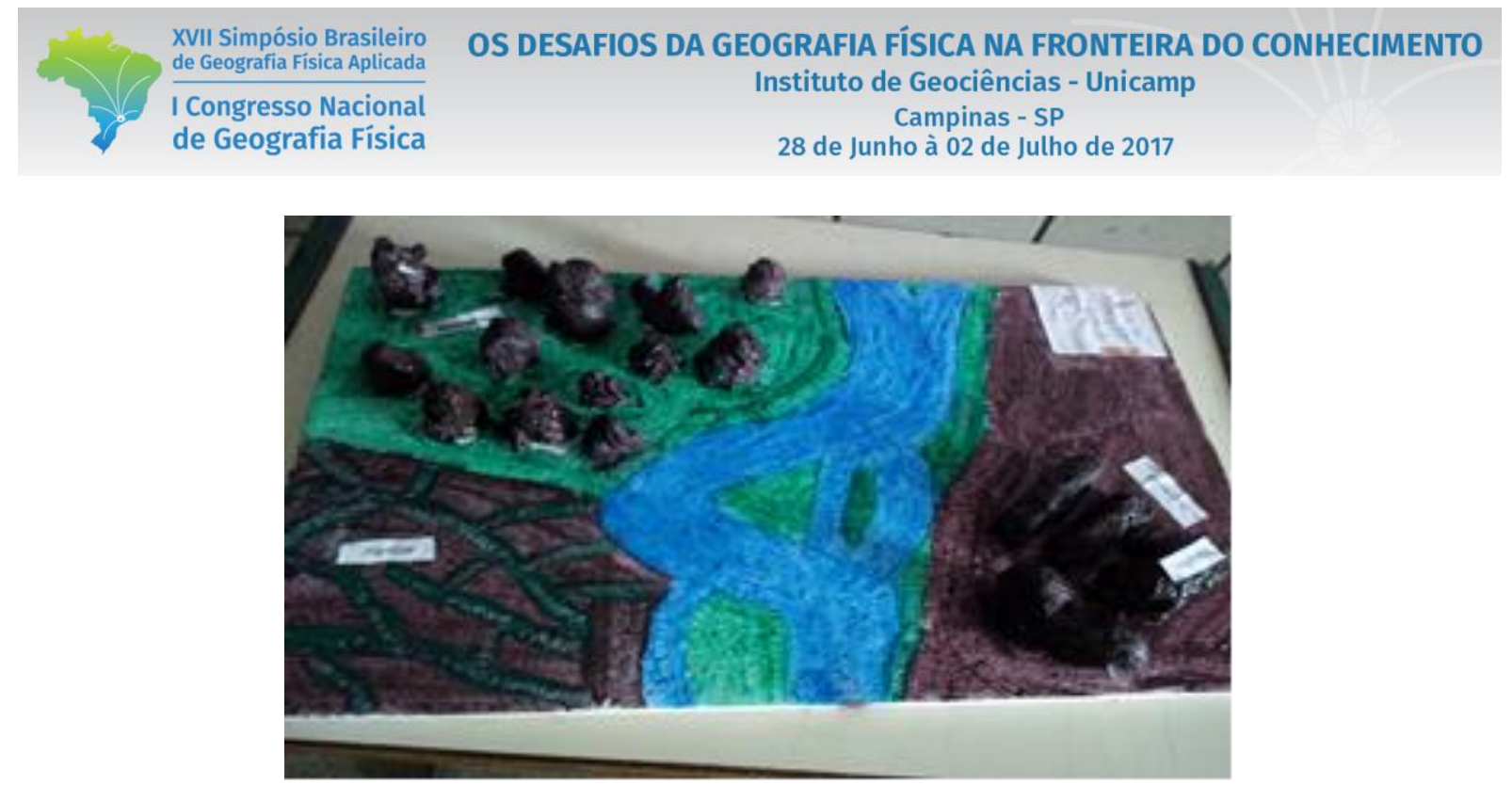

Figura 1 - Trabalho do grupo 1: Maquete representando as quatro formas de relevo, e rios e vegetação. (Foto: Thais dos Anjos, 2017)

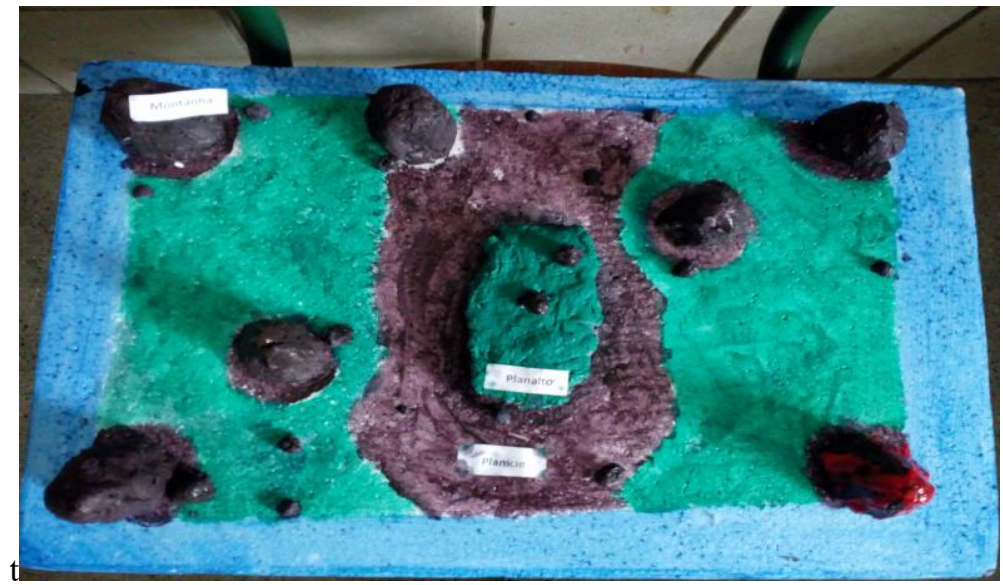

Figura 2 - Trabalho do grupo 2: Maquete representando planalto, planície e montanhas, com vegetação, rios e vulcão. (Foto: Thais dos Anjos, 2017)

\section{Considerações finais}

O estudo da geomorfologia, nos propicia analisar a paisagem, sendo assim, essencial para o aluno em sua evolução de conhecimentos sobre o espaço. Para este estudo ser realizado de forma mais satisfatória, a produção de recursos didáticos é uma ótima forma de levar a criatividade e aprendizagem mais além dentro da sala de aula. Essa é uma estratégia que não beneficia só o aluno, como também ao professor, que ambos possuem interação. Os materiais didáticos tridimensionais - as maquetes - ajudam a representar aquilo que foi aprendido através do conteúdo visto em sala de aula, e é assim que o aluno, com ajuda do educador, planejará e criará, a partir de seus conhecimentos, um material pedagógico, representando a realidade e o que aprendeu com e sobre ela.

Com base nos resultados deste trabalho, podemos afirmar que a produção das maquetes, contribuiu para que a aprendizagem dos alunos ocorresse de forma mais efetiva, e por ser uma forma de aula dinâmica, a satisfação deles fez com que o conteúdo apresentado fosse apreendido de forma mais eficaz, e assumiram a responsabilidade em desempenhar um ótimo trabalho com base nas teorias, imagens representadas no slide, dicas e orientações. A aplicação do questionário serviu para analisar o conhecimento prévio deles e comparar com o final da aula, que com o conteúdo explanado em linguagem fácil, possibilitou um bom 
entendimento. No entanto, esta foi uma forma de demonstrar que os conteúdos não podem ficar só em leituras, mas também devem ser transmitidos/produzidos com dinâmicas que possibilitem praticar o que está sendo aprendido - e a confecção de um material lúdico, como na elaboração da maquete neste projeto, foi exemplo disso.

\section{Agradecimentos}

À escola, que me recebeu com toda dedicação e respeito, principalmente a coordenadora, na qual permitiu-me realizar carinhosamente este projeto.

\section{REFERÊNCIAS}

BATISTA, Daiane Ferreira; SOUSA, Flávio Alves de. Ensino de Geomorfologia nas Escolas. II Congresso de Educação - UEG/UnU Iporá, 2012.

FALCONI, Simone. Produção de material didático para o ensino de solos. 2004. 115 f. Dissertação (mestrado) Universidade Estadual Paulista, Instituto de Geociências e Ciências Exatas, 2004.

FREITAS, Olga. Equipamentos e materiais didáticos. Brasília: Universidade de Brasília, 2009.

SILVA, Evellyn Ledur da; GIORDANI, Estela Maris. Aprendizagens de professores e alunos com materiais didáticos nos anos iniciais do ensino fundamental. IX Congresso Nacional de Educação -EDUCERE, 2009.

NALIN, Simone. Geoatividades: Maquetes com as formas de relevo. Disponível em: $<$ http://geografiadaprofessorasimone.blogspot.com.br/2012/07/maquetes-com-as-formas-de-relevo.html> Acesso em: 15 de Jan 2017. 